\title{
SOBRE A SEMIÓTICA DAS CULTURAS DE FRANÇOIS RASTIER
}

\author{
SUR LA SÉMIOTIQUE DES CULTURES DE \\ FRANÇOIS RASTIER
}

Tradução do original francês: Lia Kurts-Wöste sur la sémiotique des cultures de françois rastier (inédit) por

Flaviano Batista do Nascimento e Maria de Fátima B. de M. Batista

\begin{abstract}
RESUMO: A semiótica das culturas, herdeira tanto de Cassirer quanto do autógrafo Saussure, permite, hoje, repensar a responsabilidade dos pesquisadores em modelar seus objetos e construir uma interdisciplinaridade exigente. Ela demonstra o poder federativo da metodologia das ciências da cultura e do primeiro estruturalismo, explorando seus princípios críticos, históricos e comparativos para abordar tanto os objetos culturais, quanto as disciplinas que os explicam. A atividade científica hermenêutica é repensada em sua dimensão de ato interpretativo responsável, reconectando, de forma original, as esferas científica, artística e ético-política, por meio da exploração dos pontos de convergência entre humanismo, humanidade e Humanidades.
\end{abstract}

Palavras chave: Semiótica; linguística; antropologia; hermenêutica; cultura; obra (Rastier, Cassirer, Saussure).

\section{Situação}

A semiótica das culturas, tal como foi elaborada pela pena de François Rastier, após os anos 90. Dando continuidade a seus trabalhos da linguística neo-saussurriana sobre a semântica textual, procede de uma teoria geral das formas culturais e de suas metamorfoses herdadas da Filosofia das formas simbólicas de E. Cassirer. As publicações de F. Rastier sobre a textualidade e a semântica interpretativa são numerosas e constituem um corpus de referência na paisagem atual da pesquisa - em particular nos departamentos de língua e de literatura. Aliás, a Introdução às ciências da cultura publicada em 2002 pela PUF, em colaboração com Bouquet, forneceu os elementos preciosos de contextualização histórica e de problematização de desafios concernentes ao novo "continente" científico, inexistente até o presente dia, de introdução à semiótica das culturas que permita uma visão sintética da sua abordagem semiótica, de suas relações com a semântica, com a textualidade, mas também com os estudos literários e a história da arte, a filosofia, a ética, ou ainda, a antropologia. Livros recentes (Apprendre pour transmettre. L'éducation contre l'idéologie managériale (Paris, PUF, 2013), Créer: Image, Langage, Virtuel (Paris-Madrid, Casimiro, 2016), Mondes à l'envers (Classiques Garnier, 2018), Faire Sens. De la cognition à la culture, Paris, (Classiques Garnier, 2018), que recolhem, em parte, trabalhos já publicados, mas que ficaram muito difíceis de acessar por estarem espalhados, fornecem, aliás, elementos que dão uma iluminação complementar às monografias existentes e permitem compreender melhor o seu alcance e os desafios.. De fato, a ambição globalizante desta elaboração teórica que faz sobre a vida dos signos, hoje bastante rara para constituir uma originalidade em si mesma, é confirmada, ou mesmo 
reforçada por estas recentes publicações, tal como o seu acentuado interesse pelas formas artísticas e a valorização da especificidade do funcionamento simbólico das obras de arte. Tal abordagem globalizante pode ser considerada, por um lado, na sua dimensão coletiva, como fazendo parte de um esforço para superar o déficit de coerência no seio das Ciências Humanas e Sociais, o que, sem dúvida, resultou do êxito considerável que conheceram no século passado e que as viu crescer e separar-se em múltiplas disciplinas especializadas, gerando, também, uma dificuldade em pensar o lugar das Humanidades no seio das Ciências Humanas e a sua relação com a ciência, com a cientificiddade. Seja como for, não podemos deixar de constatar que as múltiplas disciplinas das Ciências Humanas e Sociais penam, ou não procuram de modo algum, fazer emergir visões de conjunto, tanto mais difíceis de construir, quanto estão submersas por um fluxo incessante de informações.

As historiografias que se multiplicam hoje em dia participam, sem dúvida, desta procura de coerência e de linhas de força, assim como os apelos às abordagens pluri- ou interdisciplinares, mas continua a faltar uma base epistemológica, suficientemente sólida, para construir fundamentos críticos comuns. Sendo geralmente aceito que dois grandes paradigmas - a comunicação e a cognição - que se impõem hoje no âmbito das ciências do homem e da sociedade, há que concordar, tendo em conta a situação que acabamos de recordar sua dificuldade em federar, verdadeiramente, o campo da investigação e da sua insuficiência, ou mesmo da sua inadequação, em levar em conta a especificidade das Humanidades centradas nas obras, linguageiras ou não.

A posição da semiótica das culturas consiste assim, globalmente, em considerar que a possibilidade de repensar uma coerência no seio das ciências do homem e da sociedade passa pela sua (re)integração no continente científico das ciências da cultura.

\section{Uma abordagem geral original: um «recuo» prospectivo}

Pareceu-nos interessante começar por caracterizar a abordagem geral em que se inscreve esta teoria semiótica neo-saussurriana e neo-cassiresiana -- pelo menos que possa ser reconstituída por um trabalho de síntese, a partir das suas diversas publicações científicas -- e isto, historiando seus desafios. De fato, esta abordagem geral parece-nos consistir numa interrogação crítica das relações complexas que existem entre os diferentes critérios que regulam a prática científica em sua consistência disciplinar, coerência epistemológica e em seus critérios «exógenos» (éticos, antropológicos, socio-históricos, filosóficos ...). Tendo como « pano de fundo » uma questão subjacente capaz de reunir o conjunto das problemáticas, pode-se perguntar: existe (pode ou deve existir) nas ciências do homem e da sociedade, um ponto de vista federativo, regulador, centrado numa definição mais ou menos implícita da humanidade e/ou daquilo que é válido para o ser humano? François Rastier mostra que a própria possibilidade de fazer estas perguntas pressupõe a superação de uma forma de amnésia geral - por uma espécie de involução cientista e/ou por uma interpretação tendenciosa da reivindicação à liberdade em relação às normas como exaltação de um sujeito hipersubjetivo e anti-histórico, concebido como uma vitória do julgamento privado sobre as escolas e as instituições, interpretação que, surgida nos anos 1970 -, perdeu a capacidade de pensar em conjunto sobre aquilo que as pesquisas semióticas do início do século XX e tinham, entretanto, começado a articular, seguindo o fio condutor 
dos estudos filológicos, em particular da romanística germânica: a linguística e os estudos literários e, de um modo mais geral, a linguística e a antropologia.

É neste quadro que François Rastier interroga o caráter relativamente enganoso dos dois paradigmas (comunicação e cognição) que dominam hoje as Ciências Humanas e Sociais: a sua dificuldade em orientar, validamente, o pensamento provém assim, majoritariamente, do seu «esquecimento» desta abordagem pelas formas simbólicas que, no entanto, mais ou menos explicitamente tinham federado o campo da investigação no início do século XX e do qual Ernst Cassirer pode ser considerado como uma das figuras emblemáticas. Era a esta abordagem que cabia o mérito de ter colocado a questão, através da interrogação sobre as relações entre linguística e estudos literários (ou «Humanitários»), dos complexos vínculos entre humanismo, humanidade e humanidades. ${ }^{1}$

Gostaríamos de tentar caracterizar esta abordagem geral, original e fecunda por muitos aspectos, não só pela sua capacidade de pensar em conjunto, segundo modalidades herdadas do passado (além de Cassirer, Warburg, Saussure, há que citar os grandes hermenêuticos como Auerbach ou Panofsky) e alimentadas por novos corpora críticos (Gilbert Simondon, André Leroi-Gourhan, os resultados das recentes investigações em neurociências), linguística, antropologia, sociologia, estética, história da arte, literatura e filosofia, como puderam tentar os grandes predecessores como Cassirer, Humboldt ou ainda Lévi-Strauss, mas também pelo rigor com que se aplica a elaborar a própria possibilidade de tal pensamento globalizante, apoiando-se numa arqueologia crítica das representações, em particular das ideias linguísticas e das representações do sinal, que funde de forma notável, uma dinâmica de investigação prospectiva sobre um movimento «inverso»: não só a inversão no tempo, através de um esforço retrospectivo que a sua abordagem historicista supõe e impõe, mas também a inversão das reviravoltas proclamados, dos paradigmas dominantes e dos preconceitos ideológicos tomados, reticentes laços complexos entre pensamentos de hoje e pensamentos recentes e de antigamente com, uma clarividência cujo poder heurístico nos parece útil, hoje, à coletividade dos investigadores, à sua autorreflexão e à sua projeção no futuro. É a este título que gostaríamos de contribuir para a sua difusão e submetê-la a um olhar crítico, que será considerado aqui como a expressão da dívida simbólica que pode

1 No sentido restrito dos estudos de Letras clássicas e no sentido amplo, anglo-saxónico, das Ciências Humanas e Sociais, por vezes, compreendendo a economia, como justamente observa Xavier Darcos na sessão pública de 8 de dezembro de 2014 da Academia das Ciências Morais e Políticas, «as humanidades, em francês, não têm o mesmo significado que o inglês humanities. No mundo anglo-saxônico, esta noção designa um vasto conjunto de disciplinas universitárias: as línguas e as literaturas, a filosofia, a história, as artes, mas também a geografia e mesmo o direito. Importa ainda precisar que não existe uma definição única das humanidades que já não exista nas Ciências Humanas. Estas abrangem em parte as humanidades, uma vez que as ciências humanas anglo-saxônicas englobam disciplinas como a linguística, a filosofia, a antropologia ou a economia. Apesar desta relativa confusão, é prática generalizada na França, hoje em dia, nas universidades ou nas grandes escolas, pedir emprestado humanities aos anglo-saxões, na definição muito ampla que têm e traduzir para «humanidades». Mas, na história da nossa língua, as humanidades têm um sentido muito mais restrito: trata-se da parte do ensino secundário de outrora, baseada nas letras clássicas e, às vezes, por metonímia, englobando o ensino secundário no seu conjunto; ou: as línguas e as literaturas grega e latina, o estudo que delas se faz, o amor que se tem por elas.» É uma questão cuja retomada dá, aliás, razão para responder hoje, pelo menos em parte, às novas questões relativas ao «transumanismo» ou ao «pós-humanismo». 
ser contraída a seu respeito. Esta abordagem parece-nos capaz de constituir um vetor de orientação do pensamento e uma fonte de inspiração em todas as disciplinas das Ciências Humanas e Sociais e mesmo além delas, uma vez que estas são chamadas a serem repensadas no âmbito das ciências da cultura cujo desenvolvimento François Rastier apoia.

Este último cita, regularmente, os nomes dos principais promotores deste projeto das ciências da cultura: Emmanuel Kant, Friedrich Schlegel, Wilhelm von Humboldt, Ferdinand de Saussure, Franz Boas, Ernst Cassirer, Clifford Geertz, Claude Lévi-Strauss. Trata-se, antes de tudo, de um convite a relê-los... Com efeito, as ciências da cultura, hoje em desenvolvimento, desenham uma nova rede disciplinar genética (epigénese), etologia, antropologia, arqueologia, psicologia, semiótica e linguística (cf. Introdução às ciências da cultura, F. Rastier, S. Bouquet, ed., Paris, PUF, 2002) que, sem dúvida, chamam a integrar novas disciplinas como a sociologia ou mesmo algumas especialidades das neurociências (o que pressupõe a superação, em particular através do tema da percepção, da velha clivagem entre ciências da natureza e ciências da cultura), sobre a questão do condicionamento cultural das percepções como a epigenética pode tê-lo realçado recentemente. Com esta questão da culturalização das percepções, François Rastier se junta ao esforço epistemológico, que era também um esforço ético, de um Lévi-Strauss, quando apelava à «reconciliação do homem e da natureza», matizando a ruptura tradicional entre o mundo humano, concebido como reino da cultura e o da natureza, como a ruptura tradicional entre ciência e letras. Retomando os temas do paradigma estruturalista que nasceu no início do século XX, François Rastier coloca-se, ao mesmo tempo, como historiador de ideias, mas não para neste caminho, combinando-o com uma exploração das virtudes do futuro de tal herança, optando por esta paradoxal "inversão" prospectiva que o leva a pensar não só no Saussure no futuro ${ }^{2}$, mas também em Cassirer.

\section{As Culturas ou a cultura?}

Concebidos como «espaços de normatividade do heterogêneo», os meios culturais são assim definidos pelas suas «especificidades». E como recorda judiciosamente François Rastier, «entre especificidades, não há contradição, mas apenas diferenças», entre as quais «se pode estabelecer... uma mesma distância crítica» (Créer, p.108), enquanto as «identidades» tendem a afirmar-se como tautologias narcisistas: para evitar pensar as culturas como isolados essenciais, impõe-se portanto o plural, da mesma forma que no seio das culturas, é menos homogêneo que o heterogêneo (regulado) que é posto em evidência.

A semiótica das culturas é, portanto, uma semiótica das singularidades que se situa na esteira dos grandes projetos de antropologia cultural, orientados para a descrição das diversidades que surgiram no final do século XVIII com Wilhelm von Humboldt e Friedrich Schlegel. De fato, a diversidade parece ser um dos últimos critérios, definidores das práticas humanas, muito mais do que a inovação ou a transmissão - transmissão que o ser humano partilha com as «culturas» animais e que, por conseguinte, não é suficiente para definir a cultura como lugar dos processos de «humanização» (ao contrário do que sugere a abordagem semiótica dos culturalistas russos como Y. Lotman). Uma ética da diversidade está, portanto, no princípio da semiótica das culturas: a semiótica das culturas tem por 
objeto a diferença das línguas e a multiplicidade dos sistemas de signos; a diversidade e a heterogeneidade dos sistemas de signos refletem a diversidade das práticas.

Embora a diversidade humana seja o problema fundador das ciências sociais, não exclui a busca por um ponto de vista unificante que, opondo-se ao culturalismo identitário, completa a epistemologia da diversidade: trata-se, portanto, de evitar cair num localismo e num relativismo, esquecidos da sua dimensão crítica e que tenderia a fazer da sua prevenção contra as essencializações, a justificação de certa preguiça intelectual que consiste em deixar para outros a difícil questão da generalização e a construção de um projeto federativo. Assim, a semiótica, embora seja uma semiótica das singularidades, pode-se considerar como uma abordagem das ciências da cultura. A semiótica das culturas não concebe, portanto, as culturas contrárias da cultura numa relação de exclusão, mas opta por elaborar uma definição de cultura que faça simultaneamente justiça às suas diversidades, embora mantendo a possibilidade de uma mesma distância crítica em relação a todas, tentando, por outro lado, evitar todo e qualquer etnocentrismo. Trata-se de evitar pensar no singular como uma essencialização, mas ao mesmo tempo, evitar afogar o plural num relativismo que poderia confinar à indiferença.

Inscrever a noção de «cultura» num programa de investigação atual pressupõe, aliás, um trabalho de reabilitação desta última na medida em que esta foi objeto de uma desvalorização no século XX. Suspeita de «criminalidade colonialista», conforme analisou Derrida, a noção de «colonialidade» da cultura se apoiaria num malévolo «choque de civilizações", ao passo que, na perspectiva escolhida, « a cultura é uma questão mundial e a própria noção de literatura mundial e de cidadania mundial remonta ao cosmopolitismo do Iluminismo» (p.78). Sua reabilitação passa pela sua reconstrução numa rede de noções e de conceitos que a ligam, fundamentalmente, às capacidades de simbolização do ser humano.

Reabilitar a noção de «cultura» significa, também, ter a ambição de retomar, por sua conta, a «nova compreensão do ser humano» proposta por Robert Antelme, no final da segunda guerra mundial, quando a humanidade foi definida «Não por uma alma ou valores pressuposto, mas pela revolta contra a desumanização» (p.115): assim, as obras formam e ajudam a pensar na cultura como um baluarte essencial contra essa desumanização concebida como «dessimibolização». Por outro lado, abrem caminho a uma «globalização crítica» muito saudável (pág.128), independente dos mercados e das pretensões ao universalismo dos dogmatismos de todos os quadrantes. As línguas são assim ambientes e estes ambientes são obras coletivas -- que «se escrevem nas obras» individuais.

Como sublinha F. Rastier, as ciências da cultura devem ser diferenciais e comparadas, pois uma cultura só pode ser entendida de um ponto de vista cosmopolita ou intercultural: para cada uma, é o conjunto das outras culturas contemporâneas e passadas que desempenha o papel de corpus contrastivo. As culturas só podem ser descritas de forma diferenciada, tal como os objetos culturais que as compõem (textos, obras). Uma cultura não é uma totalidade: forma-se, evolui e desaparece nos intercâmbios e nos conflitos com os outros.

Pode-se, assim, distinguir a semiótica das culturas de outras abordagens culturalistas, como a culturologia ou os estudos culturais. A culturologia eslavófila, hoje fortemente ensinada na Rússia, considera que a língua russa é o reflexo da alma russa e que uma concepção do mundo foi nela depositada, naturalmente impenetrável ao não russo. Este 
tema também aparece em Heidegger, por exemplo, com a teoria do Grund, solo nacional de tradições compartilhadas - desta vez, germânicas. O determinismo nacional combina bem com as determinações biológicas (teorias das raças). Assim, o conceito de «semiosfera», proposto em 1998 por Lotman, que alcançou um grande sucesso, deve ser abordado com precaução. Se ele testemunha uma concepção semiótica da cultura e rompe com a ideia marxista, embora ela seja uma simples «superestrutura ideológica» que não modela nem modifica os indivíduos, Lotman continua a definir uma cultura como um panorama identitário, centrado no "nós", na harmonia, na interioridade, que define um interior e um exterior que, por vezes, parece uma ameaça. A própria noção de «esfera» pressupõe, de fato, certa cerca sobre si mesma. Assim, não está previsto, nestas abordagens, que a alteridade possa ser apreciada como tal e não dentro de um jogo de repulsão/assimilação, nem que, na «tradução», ou na transposição de certos elementos, uma distância possa ser mantida, porque o seu objetivo é precisamente aniquilar a alteridade. É por essa razão que a semiótica das culturas não pode seguir a culturologia.

A semiótica das culturas distingue-se, aliás, do projeto dos estudos culturais que não têm ambição científica, pois estes dizem querer perseguir o empreendimento da desconstrução e criticam aquilo a que Derrida chama «a colonialidade essencial da cultura». Nesta ótica, a própria noção de «cultura» seria uma alienação imposta pelos dominantes: segue-se uma essencialização polêmica dos dominados.

O que a semiótica das culturas mostra é que as ciências do homem e da sociedade têm necessidade de uma concepção não ontológica da totalidade, pois uma cultura nunca é autárquica e, mesmo em condições de isolamento, desenvolve-se a partir de uma história partilhada. Assim, nesta ótica, o conceito de globalidade parece preferível ao de totalidade, pois desenha uma cerca relativa e não mais absoluta. A tradição filosófica, ontológica, sempre pensou a totalidade sob a forma de hênade ou mônade, duas entidades, uma máxima, a outra mínima, mas ambas fechadas e estáticas. Em vez de uma totalidade autárquica, a semiótica das culturas valoriza uma globalidade interativa.

Tal abordagem da cultura baseia-se na descrição das línguas de cultura ${ }^{3}$ (meios atravessados por normas e valores), que são transnacionais e invalidam a noção de «literatura nacional» (e, a fortiori, a noção de «identidade nacional»). Assim, por exemplo, o alemão de Kafka é trabalhado pelo checo e odiado pelo iídiche e, mesmo uma obra aparentemente monolíngue, pode conter um sentimento de traduções implícitas e reformuladas.

$3 \quad$ As línguas da cultura são definidas em contraste com as línguas de serviço, ou línguas veiculares, como o inglês internacional hoje (o inglês também existe, é claro, como uma língua de cultura), que são desprovidas de corpus e história: veja, por exemplo. C. Joubert, Critique de l'anglais, Lambert-Lucas, 2015. 


\section{Bibliografia (obras pessoais ou em codireção)}

Lia Kurts-Wöste, Mathilde Vallespir, Marie-Albane Rioux-Watine (dir.), Éthique et significations. La fidélité en art et en discours, en co-dir. avec Louvain-la-Neuve, Ed. Bruylant-Academia, coll. Au coeur des textes n5, 2007, 202 p.

Lia Kurts-Wöste, Mathilde Vallespir, Marie-Albane Rioux-Watine (dir.), La violence du logos. Entre sciences du texte, philosophie et littérature, Paris, Classiques Garnier, 2013, 186 p.

La simplicité. Enjeux et manifestations du simple en art, en co-dir. avec Sophie JollinBertocchi, Anne-Marie Paillet et Claire Stolz, Paris, Ed. H. Champion, 2017, 541 p.

Lia Kurts-Wöste, Astrid Guillaume (dir.), Faire science, faire sens, Londres, éd. ISTE (2019). 